\title{
A questão de gênero numa perspectiva decolonial
}

Gabriella da Silva Mendes ${ }^{1}$, Alexandre Brasil Carvalho da Fonseca ${ }^{2}$

\section{Resumo}

Este artigo tem por objetivo refletir a respeito das questões de gênero, a partir da perspectiva de análise da decolonialidade. Estudos da temática mostram que o gênero pode ser uma forma de colonialidade, que produz discursos que escondem a multiplicidade da vivência das relações fora do "sistema mundo da colonial modernidade". Dessa forma, tentaremos compreender como as relações de gênero se viram modificadas historicamente pelo colonialismo, a partir de uma breve revisão de literatura, para pensar nas possibilidades de uma perspectiva decolonial para a questão de gênero. Utilizando como metodologia a revisão sistemática, este artigo não se pretendeu a responder tão complexas questões que abordam o tema, e sim realizar um mapeamento.

\section{Palavras-chave:}

Gênero. Decolonialidade.

\footnotetext{
${ }^{1}$ Mestre em Educação, Ciência e Saúde pela Universidade Federal do Rio de Janeiro, Brasil; editora da Página de Divulgação Científica e História da Ciência: Meninas na Ciência. E-mail: gabiufrj1@ @mail.com.

${ }^{2}$ Doutor em Sociologia pela Universidade de São Paulo, Brasil, com estágio de pós-doutoramento na Universidade de Barcelona, Espanha; professor associado da Universidade Federal do Rio de Janeiro, Brasil; diretor do Instituto NUTES de Educação em Ciências e Saúde. E-mail: abrasil@ufrj.br.
} 


\title{
The issue of gender in a decolonial perspective
}

Gabriella da Silva Mendes ${ }^{3}$, Alexandre Brasil Carvalho da Fonseca ${ }^{4}$

\begin{abstract}
This article aims to reflect on gender issues from the perspective of decoloniality analysis. Studies of the theme show that gender can be a form of coloniality, which produces discourses that hide the multiplicity of the experience of relations outside the "world system of colonial modernity". In this way, we will try to understand how gender relations have been historically modified by colonialism, from a brief literature review, to think about the possibilities of a decolonial perspective to the gender issue. Using the systematic review as a methodology, this article was not intended to answers such complex questions which address the topic, but to perform a mapping.
\end{abstract}

\section{Keywords}

Gender. Decoloniality.

\footnotetext{
${ }^{3}$ Master in Education, Science and Health, Federal University of Rio de Janeiro, State of Rio de Janeiro, Brazil; editor of the Science Dissemination and History of Science page: Girls in Science. E-mail: gabiufrj@gmail.com.

${ }^{4} \mathrm{PhD}$ in Sociology, University of São Paulo, Brazil, with a postdoctoral internship at the University of Barcelona, Spain; associate professor at the Federal University of Rio de Janeiro, State of Rio de Janeiro, Brazil; director of the NUTES Institute of Education in Science and Health. E-mail: abrasil@ufrj.br.
} 


\section{Introdução}

Há alguns anos, a produção de um grupo de intelectuais latino-americanos e de outros países do hemisfério sul, de diversas áreas de conhecimento, tem se conformado como uma nova e interessante referência para o campo da educação, denominada pós-colonial, e que tem como um de seus focos abordarem a questão da decolonialidade ${ }^{5}$.

Esses autores decoloniais incluem, a saber: o filósofo argentino Enrique Dussel; o sociólogo peruano Aníbal Quijano; o semiólogo e teórico cultural argentino Walter Mignolo; o sociólogo porto-riquenho Ramón Grosfoguel; o psiquiatra, filósofo e ensaísta marxista francês da Martinica, de ascendência francesa e africana Frantz Fanon; a linguista norteamericana radicada no Equador Catherine Walsh; a filósofa argentina Maria Lugones; a cientista política brasileira Luciana Ballestrin; a socióloga e historiadora boliviana Silvia Rivera Cusicanqui; a antropóloga argentina Rita Laura Segato; a teórica literária indiana Gayatri Chakravorty Spivak; a antropóloga social afro-dominicana Ochy Curiel; a estudiosa norte-americana da teoria cultural chicana Gloria Anzaldúa; o filósofo porto-riquenho Nelson Maldonado-Torres; o antropólogo colombiano Arturo Escobar, dentre outros (OLIVEIRA, 2010).

Conforme Oliveira (2010, p. 15-38),

O termo decolonial deriva de uma perspectiva teórica que estes autores expressam, fazendo referência às possibilidades de um pensamento crítico a partir dos subalternizados pela modernidade capitalista e, na esteira dessa perspectiva, a tentativa de construção de um projeto teórico voltado para o repensamento crítico e transdisciplinar, caracterizando-se também como força política para se contrapor às tendências acadêmicas dominantes de perspectiva eurocêntrica de construção do conhecimento histórico e social. ${ }^{6}$

Segundo Ballestrin (2013), a expressão “decolonial” não pode ser confundida com “descolonização". Em termos históricos e temporais, essa última indica uma superação do colonialismo; por seu turno, a ideia de decolonialidade atua no sentido da superação do par modernidade/colonialidade e tudo o que ele representa, o qual permanece operando ainda nos dias de hoje em um padrão mundial de poder, como discutido:

\footnotetext{
${ }^{5}$ Decolonialidade é um termo usado principalmente por um movimento latino-americano emergente que se concentra na compreensão da modernidade no contexto de uma forma de teoria crítica aplicada a estudos étnicos e, cada vez mais, também em estudos de gênero (BALLESTRIN, 2013).

${ }^{6}$ Elaboração cunhada pelo grupo Modernidade/Colonialidade nos anos 2000 e que pretende inserir a América Latina de uma forma mais radical e posicionada no debate pós-colonial, muitas vezes criticado por um excesso de culturalismo e mesmo eurocentrismo devido à influência pós-estrutural e pós-moderna.
} 
Preferimos utilizar o termo "decolonial" e não "descolonial". O conceito em inglês é decoloniality; sobre esse termo existe um consenso entre os autores vinculados a essa perspectiva de estudo. Já com relação à tradução para espanhol e português não há uma posição unânime. Entretanto, preferimos o termo decolonial, pelos mesmos motivos que Walsh (2009, p. 15-16). A autora prefere utilizar o termo "decolonial", suprimindo o "s" para marcar uma distinção com o significado de descolonizar em seu sentido clássico. Deste modo quer salientar que a intenção não é desfazer o colonial ou revertê-lo, ou seja, superar o momento colonial pelo momento pós-colonial. A intenção é provocar um posicionamento contínuo de transgredir e insurgir. O decolonial implica, portanto, uma luta contínua. (COLAÇO, 2012, p. 7-8).

Suprimir la "s" y nombrar "decolonial" no es promover un anglicismo. Por el contrario, es marcar una distinción con el significado en castellano del "des". No pretendemos simplemente desarmar, deshacer o revertir lo colonial; es decir, pasar de un momento colonial a un no colonial, como que fuera posible que sus patrones y huellas desistan de existir. La intención, más bien, esseñalar y provocar un posicionamiento - una postura y actitud continua - de transgredir, intervenir, in-surgir e incidir. Lo decolonial denota, entonces, un camino de lucha continuo en el cual podemos identificar, visibilizar y alentar "lugares" de exterioridad y construcciones alternativas. (WALSH, 2009, p. 14-15).

Gonzatto (2015) explica que para os autores que sustentam a necessidade de utilização da expressão "decolonial", como Catherine Walsh, o prefixo "des" indicaria que os objetivos dessa corrente estariam sintetizados somente por meio da superação do colonialismo. Entretanto, no sentido político e estratégico, reconhece-se que a utilização do termo "descolonial" é mais utilizada nos artigos científicos traduzidos para o português de autores que utilizam a expressão "descolonização" não como simples superação do colonialismo, mas, como síntese de uma ferramenta política, epistemológica e social de construção de instituições e relações sociais realmente pautadas pela superação das opressões e das estruturas que conformam uma geopolítica mundial extremamente desigual.

Ao realizar essa reflexão, percebemos as operações de exclusão e desumanização mediante a produção da diferença colonial, na qual o discurso da emancipação colocou em prática séculos de violenta dominação sobre os povos colonizados.

\section{Fundamentação do problema}

Ao realizarmos uma breve caracterização dos estudos decoloniais, apesar de notarmos uma vertente de perspectiva contestatória ao padrão colonial como forma de resistência e tentativa de novos esforços à perpetuação da relação ao eurocentrismo, ao colonialismo e ao imperialismo intelectual exercidos pelos centros de produção do conhecimento acadêmico, 
percebemos certo silenciamento ou ainda a manutenção de invisibilidade para autoras que discutem sobre decolonialidade, sobretudo dentro da área temática de gênero, com predominância nos discursos de autores homens.

Dentro dos discursos decoloniais, ainda percebemos a temática de gênero inserida como uma subcategoria, escrita por autores homens. Autores como Anibal Quijano (2010) discutem que a raça é a categoria que forma o sistema-mundo da colonialidade é insuficiente e mesmo "totalizante" ao invisibilizar o gênero (MENDOZA, 2010, p. 24), além de essencialista e naturalizadora, pois, toma o sexo como dado da natureza, organizado e organizando sempre da mesma forma as relações entre os sujeitos.

É nesse contexto que passa a ser realizada uma análise de gênero da colonialidade - ou um gênero decolonial - para pensar como as normas de gênero fazem parte da colonialidade do poder, do saber e do ser. Passa-se a falar também da colonialidade do gênero, passa-se a pensar que tanto o gênero é informado pela raça, quanto à raça é informada pelo gênero.

Entender não ser possível falar em gênero sem pensar a colonialidade, nem falar de colonialidade sem incluir o gênero. Isso significa, então, que também não há como partir de perspectivas em que o gênero passa a ser a categoria explicativa central e principal e a raça algo que cria matizes ou particularidades dentro de um suposto sistema primário de opressão organizado pelo gênero. (ESPINOSA-MIÑOSO, 2014, p. 11-12).

Uma análise decolonial, segundo Espinosa-Miñoso (2014) pressupõe que se pense como raça (e classe) e gênero (re) produzem-se reciprocamente nessa construção moderna binária. É por isso que usar o gênero como categoria de análise em um trabalho brasileiro e latino-americano precisa se transformar em usar o gênero como categoria de análise decolonial: mais do que falar de interseccionalidade de raça, classe e gênero, de analisar como essas categorias de opressão funcionam criando experiências diferentes. Trata-se de analisar como essas categorias juntas, trabalhando em redes, são ao mesmo tempo causa e efeito na criação dos conceitos umas das outras.

Isso significa dizer que a forma como compreendemos o gênero depende de como compreendemos a raça e a classe, e o contrário igualmente. Passa por pensar como "categorias de branquitude e negritude, masculinidade e feminilidade, trabalho e classe passaram a existir historicamente desde o início" (MCCLINTOCK, 2010, p. 39), não para analisar como a raça afeta um grupo específico de mulheres, mas, para realizar análises que levem a sério a "colonialidade e o racismo - não mais como fenômeno, mas como episteme intrínseca a modernidade e seus projetos libertadores - e sua relação com a colonialidade de gênero", abandonando a mulher universal vista sob um sistema único de opressão. (ESPINOSA-MIÑOSO, 2014, p. 12). 
Nessa discussão cabe refletirmos: quais as identidades e contribuições das autoras decoloniais nessa perspectiva de construção de conhecimento?

Ao realizarmos um mapeamento das principais autoras fundadoras decoloniais, nos aprofundaremos nas reflexões de seus principais temas de discussões, para isso selecionando alguns de seus principais trabalhos: Catherine Walsh (2009; 2013), cujas reflexões perpassam principalmente sobre os processos dos movimentos indígenas e afrodescendentes, especialmente na América Latina; Maria Lugones (2008), procurando debater as interseções entre raça, classe, gênero e sexualidade; Luciana Ballestrin (2013), cuja análise central está na constituição, trajetória e o pensamento dos intelectuais latino-americanos sobre Modernidade/Colonialidade; Silvia Rivera Cusicanqui (2010) preocupa-se em investigar a participação indígena andina nas revoltas da era colonial, utilizando-se principalmente da metodologia de história oral; Rita Laura Segato (2012), cujas investigações centram-se sobre questões de gênero nos povos indígenas e comunidades latinas americanas sobre violência de gênero e as relações entre gênero, racismo e colonialidade. Gayatri Chakravorty Spivak (2010), cuja análise está preocupada na representação nos contextos: político, econômico e social, tanto para quem representa, como para os que são representados, bem como a questão da consciência e da conscientização da resistência da/na subalternidade; Ochy Curiel (2009), cujas pesquisas procuram estabelecer o movimento de mulheres afro-caribenhas e afirmar que o lesbianismo não é uma identidade, orientação ou preferência sexual, mas, ao invés, uma posição política.

\section{Metodologia}

Optou-se por realizar uma revisão sistemática ${ }^{7}$ de literatura a partir do Portal de Periódicos CAPES/MEC ${ }^{8}$.

\footnotetext{
${ }^{7}$ Segundo Galvão e Pereira (2014), as revisões sistemáticas são consideradas estudos secundários, que têm nos estudos primários sua fonte de dados. Entende-se por estudos primários os artigos científicos que relatam os resultados de pesquisa em primeira mão. São mais frequentes as revisões sistemáticas de ensaios clínicos randomizados. No entanto, há número crescente de revisões preparadas com base em investigações observacionais, como as de coorte, de caso-controle, transversal, série e relato de casos. Outros delineamentos utilizados são os estudos de avaliação econômica e os qualitativos. Quando se verifica que os estudos primários incluídos em revisão sistemática seguem procedimentos homogêneos, os seus resultados são combinados, utilizando-se técnicas de metanálise. Os métodos para elaboração de revisões sistemáticas preveem: (1) elaboração da pergunta de pesquisa; (2) busca na literatura; (3) seleção dos artigos; (4) extração dos dados; (5) avaliação da qualidade metodológica; (6) síntese dos dados (metanálise); (7) avaliação da qualidade das evidências; e (8) redação e publicação dos resultados.

${ }^{8}$ Disponível em: http://www.periodicos.capes.gov.br.
} 
Para realização da primeira etapa do presente trabalho, quisemos mapear quantitativamente o número de artigos que abordavam nossa questão central sobre gênero na decolonialidade, usando diversas combinações de palavras-chave que perpassam o tema, tais como: colonialidade, com 544 artigos; colonialidade e gênero, com 151 artigos; colonialidade e feminino, com 21 artigos; colonialidade e feminista, com 59 artigos; colonialidade e mulher, com 42 artigos; decolonialidade, com 76 artigos; decolonialidade e gênero, com 24 artigos; decolonialidade e feminino, com 3 artigos; decolonialidade e feminista, com 7 artigos; decolonialidade e mulher, com 7 artigos; colonial, com 568 artigos; colonial e gênero, com 530 artigos; colonial e feminino, com 462 artigos; colonial e feminista, com 101 artigos; colonial e mulher, com 100 artigos; decolonial, com 371 artigos; decolonial e gênero, com 288 artigos; decolonial e feminino, com 8 artigos; decolonial e feminista, com 181 artigos; decolonial e mulher, com 16 artigos.

$\mathrm{Na}$ segunda etapa, após buscarmos na literatura, aplicamos para análise desses resultados obtidos o filtro para publicações revisadas por pares, totalizando 3.683 artigos, abrangendo os resultados obtidos com as diferentes combinações de palavras-chave.

$\mathrm{Na}$ terceira etapa, como forma de análise quantitativa também em outros idiomas, optamos por realizar a busca no Portal de Periódicos CAPES/MEC em língua estrangeira (espanhol e inglês), também pensando em diversas combinações de palavras-chave, que perpassam o tema como: colonialidad, com 149 artigos; colonialidad y género, com 156 artigos; colonialidad y feminino, com 89 artigos; colonialidad y feminista, com 136 artigos; colonialidad y mujer, com 262 artigos; descolonialidad, com 90 artigos; decolonialidad y género, com 19 artigos; decolonialidad y feminina, com 1 artigo; decolonialidad y feminista, com 20 artigos; decolonialidad y mujer, com 29 artigos; colonial, com 949 artigos; colonial y género, com 205 artigos; colonial y feminina, com 136 artigos; colonial y feminista, com 101 artigos; colonial y mujer, com 417 artigos; decolonial, com 718 artigos; decolonial y género, com 122 artigos; decolonial y feminino, com 59 artigos; decolonial y feminista, com 181 artigos; decolonial y mujer, com 204 artigos; coloniality, com 731 artigos; coloniality and gender, com 359 artigos; coloniality and feminine, com 531 artigos; coloniality and feminist, com 190 artigos; coloniality and woman, com 313 artigos; decoloniality, com 616 artigos; decoloniality and gender, com 252 artigos; decoloniality and female, com 87 artigos; decoloniality and feminist, com 153 artigos; decoloniality and woman, com 117 artigos; colonial, com 685 artigos; colonial and gender, com 860 artigos; colonial and feminine, com 919 artigos; colonial and feminist, com 143 artigos; colonial and woman, com 370 artigos; decolonial, com 613 artigos; decolonial and gender, com 517 artigos; decolonial and female, 
com 754 artigos; decolonial and feminist, com 264 artigos; decolonial and woman, com 912 artigos.

$\mathrm{Na}$ quarta etapa, após buscarmos na literatura estrangeira espanhola as diferentes combinações de palavras-chave, obtivemos como resultados 4.043 artigos em espanhol. Após as análises desses artigos, aplicando o filtro para publicações revisadas por pares, obtivemos um total de 3.012 artigos em espanhol.

Ainda nessa mesma etapa, após buscarmos na literatura estrangeira inglesa as diferentes combinações de palavras-chave, obtivemos como resultados: 9.386 artigos em inglês. Após as análises desses artigos, aplicando o filtro para publicações revisadas por pares, obtivemos um total de 7.450 artigos em inglês.

$\mathrm{Na}$ quinta etapa, com o intuito de realizar um mapeamento a respeito das autoras decoloniais, utilizamos a base de dados do Portal Scielo ${ }^{9}$ com as mesmas combinações de palavras-chave descritas acima, encontramos cerca de: 390 artigos em Português; 756 artigos em Espanhol; 1.547 artigos em Inglês.

Na sexta etapa, após a análise desses resultados obtidos com a aplicação do filtro para publicações revisadas por pares abrangendo os resultados obtidos com relação às autoras com as mesmas combinações de palavras-chave descritas acima, totalizaram-se: 350 artigos em Português; 585 artigos em Espanhol; e 703 artigos em Inglês.

$\mathrm{Na}$ sétima etapa, após a extração de todos os dados e análise dos resultados (quantitativamente e qualitativamente), realizando dessa forma uma síntese dos dados, optamos por trabalhar com a investigação dos 24 artigos encontrados durante as buscas com a palavra-chave: decolonialidade e gênero, eixo central da discussão que pretendemos desenvolver no presente trabalho.

Ainda nessa sétima etapa, realizando o mapeamento com relação às autoras decoloniais, iremos trabalhar com os três artigos encontrados durante as buscas com a palavra-chave: decolonialidade e gênero, que foram das autoras: Cusicanqui (2010); Walsh (2013) e Segato (2012). Nessas buscas, percebemos que os três artigos são os mais citados nas pesquisas relacionadas a decolonialidade e gênero.

$\mathrm{Na}$ oitava etapa, avaliando qualitativamente as evidências observamos também durante o processo de pesquisa que 9 áreas temáticas perpassam os 24 artigos: Antropologia (12); Ciências Políticas (4); Estudos de Caso (2); Estudos Culturais (1); Estudos Éticos (1); Estudos da Mulher (1); Estudos e Pesquisa Educacional (1); Questões Sociais(1); Sociologia (1). E

\footnotetext{
${ }^{9}$ Disponível em https://www.scielo.org/.
} 
com relação às autoras decoloniais nos artigos que encontramos, eles perpassam 3 áreas temáticas: Antropologia (1); Ciências Políticas(1); Humanidades, Multidisciplinar (1).

Durante a utilização metodológica da revisão sistemática para a escrita desse trabalho, tivemos a possibilidade de perceber como, mesmo após o início desse método e de um processo abrangente para responder uma questão específica de pesquisa, ele: localiza, avalia e sintetiza um conjunto de evidências que estão presentes em vários estudos científicos que vamos encontrando conforme caminhamos em nossa pesquisa, mas que durante o percurso nos permite obter uma visão geral do tema que estamos pesquisando. Conhecer vários tipos de abordagens temáticas de trabalhos de pesquisa que estão inseridos no tema que estamos analisando, conforme percorremos esse caminho metodológico, possibilitou a redação e publicação dos resultados a seguir.

\section{Resultados e Discussão}

Gráfico 1 - Resultados gerais da Base de Dados do Portal de Periódicos CAPES/MEC

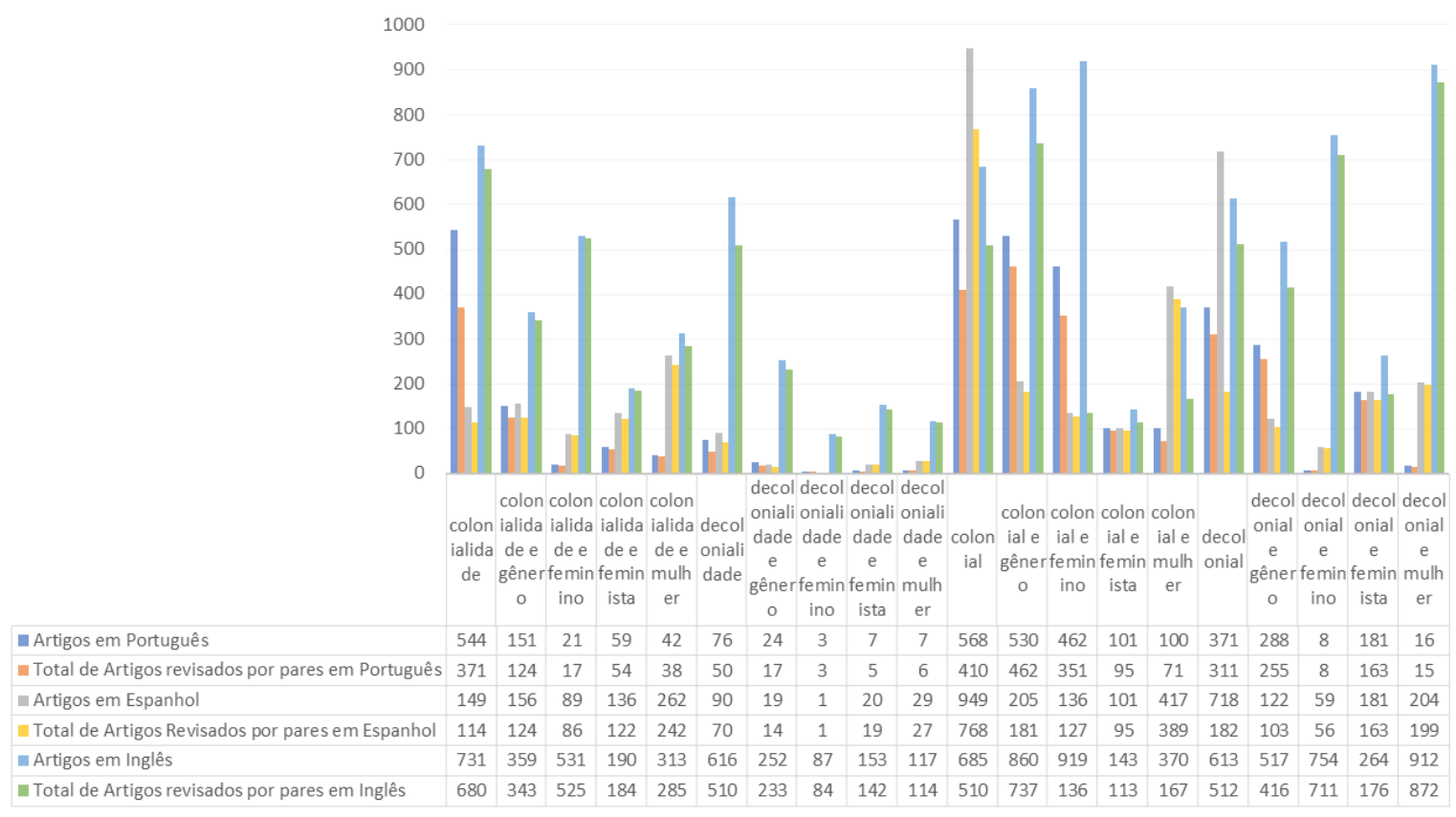

Fonte: Os autores (2019). 
Gráfico 2 - Resultados gerais de Artigos de Mulheres na Base de Dados Scielo

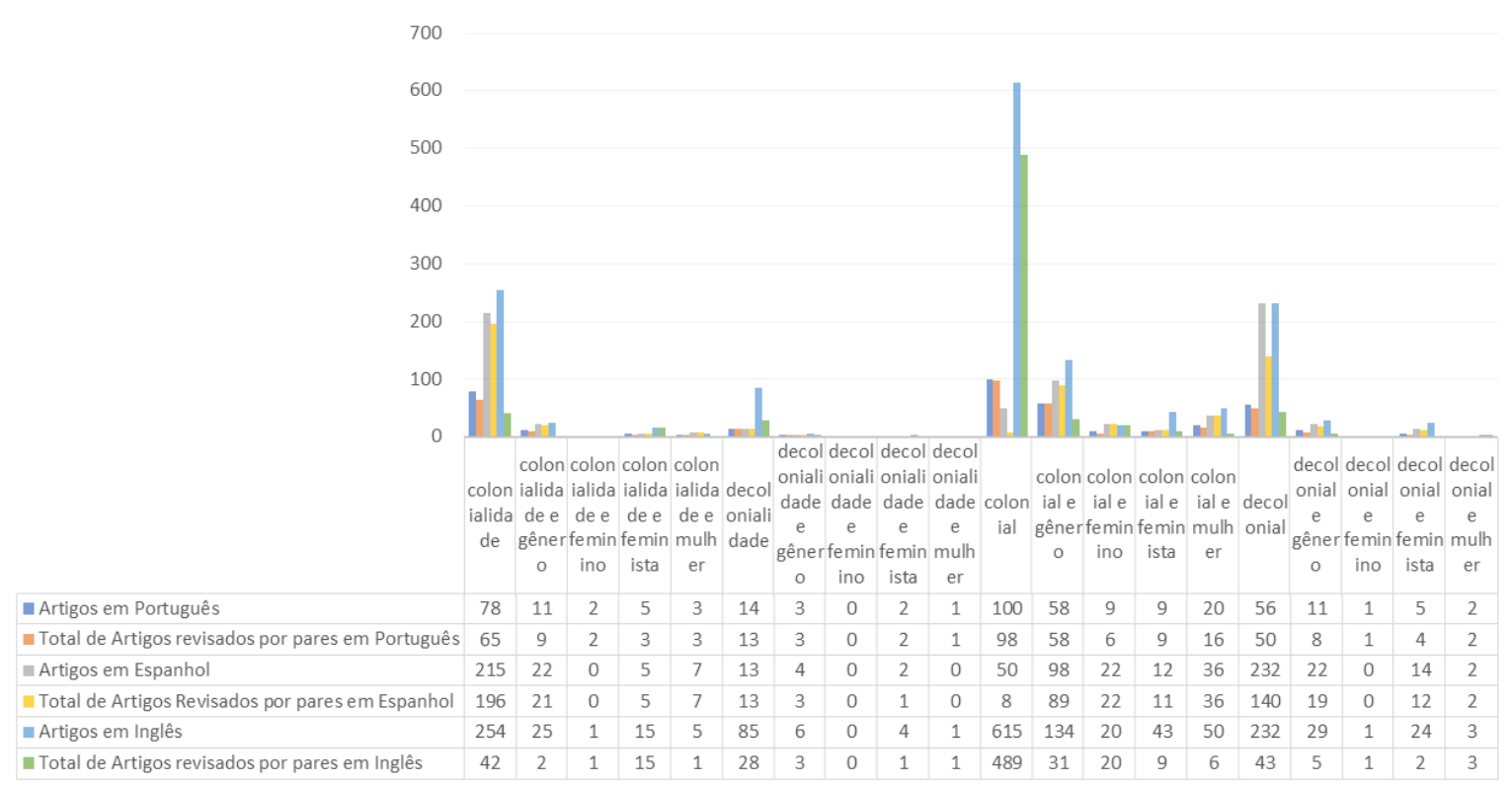

Fonte: Os autores (2019).

Gráfico 3 - Publicações de Decolonialidade e Gênero em áreas temáticas, escolhidas para serem exploradas neste artigo

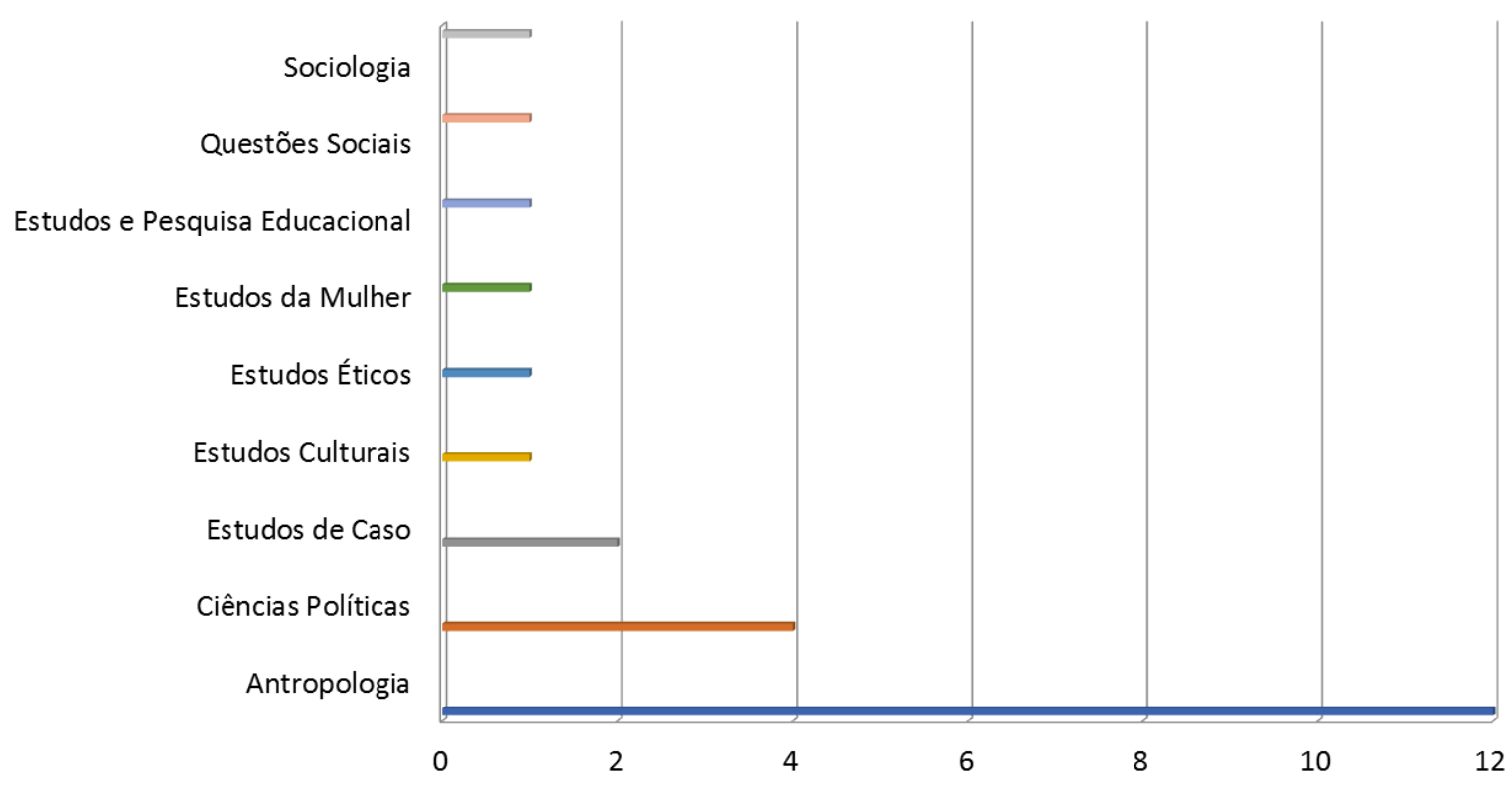

Fonte: Os autores (2019). 
Gráfico 4 - Publicações de Decolonialidade e Gênero em áreas temáticas escolhidas para serem exploradas neste artigo e publicados por mulheres

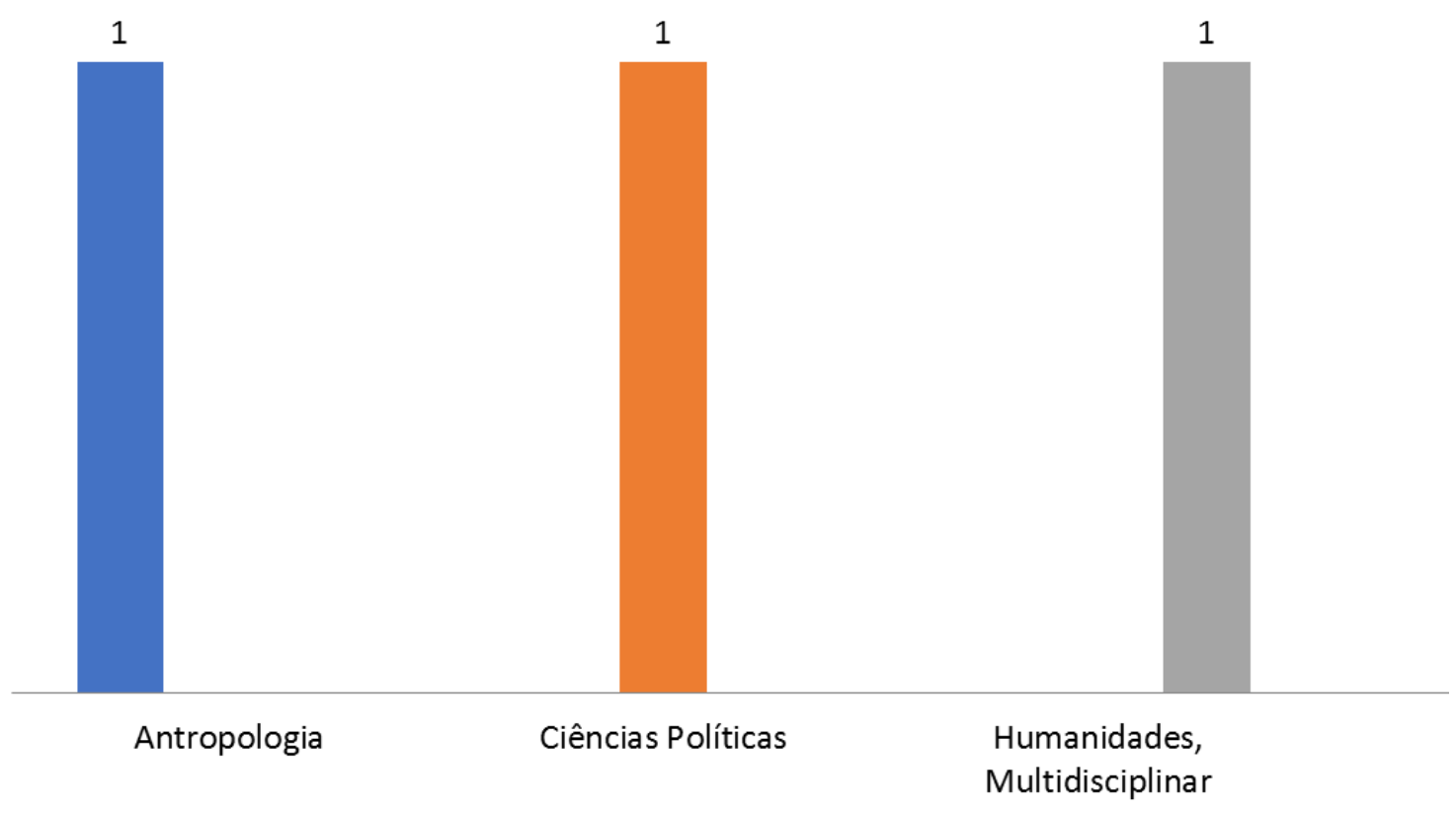

Fonte: Os autores (2019)

Durante as análises dos artigos encontrados na revisão podemos refletir sobre o delineamento de como o gênero se fez presente no processo de construção das interações póscoloniais.

Podemos observar, segundo Dias (2013), como teorias de colonialidade inicialmente não consideraram as implicações do gênero no processo de construção das dicotomias de poder, por isso é importante relacionar o gênero como categoria de dominação, categoria fundamental na instituição e fundação da Modernidade/Colonialidade.

Podemos perceber que, ao abordarem essa temática como argumentações centrais, encontram-se os artigos analisados, como os defendidos nas pesquisas de Dias (2013), que categorizou:

a) Apresentar os conceitos centrais (poder, saber e ser) dos estudos sobre decolonialidade e a relação destes com os estudos coloniais e pós-coloniais, além da reflexão sobre a modernidade; b) Explicar o conceito central de gênero moderno e colonial e o feminismo decolonial; c) Justificar a intersecção dos estudos de colonialidade e de gênero. (DIAS, 2013, p. 2).

Segundo Oliveira e Candau (2010), a partir dos conceitos centrais de colonialidade do poder, do saber e do ser, houve a possibilidade para construir o conceito de colonialidade de gênero para surgir a categoria gênero e decolonialidade e mais recentemente se falar em feminismo e decolonialidade. Ao refletirmos as desigualdades de gênero na perspectiva 
decolonial, ancorando-nos ao fato de que a colonialidade é constitutiva da modernidade e que ela não pode ser entendida sem levar em conta os nexos com a herança colonial e as diferenças étnicas que o poder moderno/colonial produziu; progredimos para dar voz às vozes não visibilizadas nas pesquisas da temática.

Nesse processo de investigação, pudemos observar que a invisibilidade é uma discussão muito presente na temática decolonialidade e gênero, relacionando-se nas discussões teóricas dos estudos sobre: subalternidade ou subalterno.

Segundo Santos (2011),

O termo "subalterno", do latim subalternus, significa "aquele que depende de outrem: pessoa subordinada à outra". Nesse estudo, tomamos "subalterno" como: expressão que se refere à perspectiva de pessoas ou grupos que estão fora do poder da estrutura hegemônica; daí o conceito de subalternidade exigir um espaço territorial definido e demarcado, bem como àqueles que se encontram fora do pensamento hegemônico, e se encontram silenciados. (SANTOS, 2011, p. 3).

Como um grande marco nos estudos de subalternidade e decolonialidade, temos o artigo: "Pode o subalterno falar?", da pensadora indiana Gayatri Spivak (2010), em que encontramos importantes reflexões e análises de "quais são os limites e possibilidades para a fala das pessoas subalternas diante da violenta dominação hegemônica?”. Buscando-se pensar e analisar todas essas questões a respeito da subalternidade, temos o campo acadêmico chamado de "estudos da subalternidade" para se pensar a identidade subalterna e como "dar reconhecimento" a mesma.

Dessa forma, os estudos da subalternidade surgem como um reconhecimento das identidades que foram colocadas em posição subalterna por uma sociedade: colonialista, branca, patriarcal, cisnormativa, heterocapitalista hegemônica. Nessa posição de subalternidade, nos estudos decoloniais, encontramos as pessoas negras em uma identidade subalterna, ou seja, foram colocadas em situação de subalternidade em relação à hegemonia branca, assim como pessoas homossexuais em uma sociedade heteronormativa, pessoas trans em uma sociedade cisnormativa, e as mulheres em uma sociedade machista e falocêntrica ${ }^{10}$.

Segundo Spivak (2010), a condição de subalternidade é a condição do silêncio, ou seja, o subalterno carece necessariamente de um representante por sua própria condição de silenciado.

\footnotetext{
${ }^{10}$ Descrição dos termos de "subalternidade" pesquisados: https://www.revistaforum.com.br/subalternidade-eoutrofobia/.
} 
Sobressai dessa forma, segundo Figueiredo (2010), o questionamento de Spivak (2010): Pode o subalterno falar? Para tanto, propõe-se a produção de uma história que represente a narrativa da verdade dos subalternos. Nesse sentido, de acordo com Spivak (2010), escrevemos como povos que tiveram a consciência formada como sujeitos coloniais e que negar isso seria negar a história. Podemos observar que a autora traz à tona a dualidade do termo representação entre o "falar por" e a "representação", nos sentidos de

[...] representação estão correndo juntos: representação como "falar por", como na política e representação como "re-presentar" como na arte ou filosofia. Uma vez que a teoria também é apenas ação, o teórico não representa o (falar por) dos grupos oprimidos. [...] Estes dois sentidos de representação dentro do estado de formação e da lei, por um lado, e a predição do sujeito por outro lado, estão relacionados, mas, irredutivelmente descontínuas. (SPIVAK, 2010, p. 275).

Refletindo sobre os questionamentos de Spivak (2010), percebemos como a autora privilegia em seu trabalho o projeto feminista, refletindo sobre a consciência da mulher subalterna nos estudos inseridos na área de decolonialidade e gênero que estamos mapeando nesse trabalho.

Analisando as reflexões da autora pensando na decolonialidade, passamos a entender o silenciamento da mulher frente ao poder e à imposição masculina:

Uma vez posta à margem da sociedade no contexto da produção colonial em que o homem é o dominante, a mulher subalterna não tem história e não pode falar, sendo colocada às sombras. A pesquisadora afirma que tal reflexão sobre a mulher não pode ser reduzida a uma mera questão idealista, uma vez que ignorar o debate acerca da mulher subalterna seria um gesto apolítico que, ao longo da história, tem perpetuado o radicalismo masculino. Dessa maneira, na busca por aprender a falar (ao invés de ouvir ou falar por) historicamente, "o assunto emudecido da mulher subalterna é sistematicamente esquecido pelo intelectual pós-colonial". (FIGUEIREDO, 2010, p. 87).

[...] subalterno não pode falar e que não há nenhuma virtude em ter a mulher nos textos globais como um item de piedade e que a intelectual feminina enquanto intelectual tem uma tarefa circunscrita da qual ela não pode se manter como um adorno. (SPIVAK, 2010, p. 308).

Ao realizarmos essa pesquisa, e reconhecer o pouco número de autoras mulheres tendo seus trabalhos reconhecidos, nos estudos sobre decolonialidade e gênero, entendemos mais uma vez, utilizando os questionamentos de subalternidade e silenciamento de Spivak (2010), como as mulheres permanecem como figuras excluídas da sociedade e da cultura dominante, 
ilustrando dessa forma, retomando as palavras da autora: "subalterno é sempre aquele que não pode falar, pois, se o fizer, já não o é”.

Observando essa exclusão/silenciamento, mais uma vez, reforçam-se como as mulheres têm seus "lugares de fala" ocupados por homens, resultando na contínua reprodução da "dominação masculina", de modo que infelizmente ainda podemos perceber uma reprodução dos resquícios coloniais mesmo nos estudos acadêmicos que se comprometem a serem "agentes de mudanças" de heranças européias coloniais excludentes, que negaram principalmente o direito de fala a: mulheres, negros, homossexuais e todos que se classificam como "à margem da sociedade".

\section{Conclusões ou Pensamentos}

Tendo em vista a vasta quantidade bibliográfica encontrada nessa pesquisa relacionada com decolonialidade e gênero, percebemos na escrita dos artigos mapeados que os principais pontos de discussão são: gênero, raça e classe.

Apesar da breve revisão de literatura, notamos que os autores referência encontrados afirmam que ainda há limitações e falta de intersecções entre gênero, raça, e classe para o aprofundamento desses estudos como parte da decolonialidade.

Durante essa análise, pôde-se perceber que: gênero, raça e classe, são categorias que devem ser examinadas em conjunto, como observado por Segato (2012), e analisado por Gomes (2018), segundo se justifica porque

[...] são produzidas em conjunto e não apenas porque produzem "estereótipos ou discriminações" diferentes quando observadas em conjunto na experiência dos sujeitos. Como forma de investigar o que a colonialidade do gênero apagou, destruiu ou invisibilizou, e como as noções de gênero da modernidade colonial que hoje são discutidas, a partir de construções que usam da raça e do sexo de modo articulado para preencher a oposição entre humanos e "não-humanos", usar o gênero como categoria de análise decolonial, significará empreender estudos que vejam que entendemos ou usamos como sexo/gênero, construído no performativo da colonialidade, tendo a raça e o racismo como informadores dessa construção. Ou seja, gênero; raça e classe não surgem como conceitos separados, mas, são forjados numa mesma matriz que tem como estrutura binária central aquela de humanos/não-humanos. (GOMES, 2018, p.77).

Nos resultados encontrados nos artigos das três autoras identificadas na revisão de literatura, a saber: Cusicanqui (2010); Segato (2012) e Walsh (2007), percebemos diferentes 
modos de pensar o gênero na perspectiva decolonial, de modo que, ao se aglutinar, condensar as demandas, e reivindicações das mulheres, inserindo-se como subcategoria em: raça e classe resultam em uma crítica à categorização generalizada desses três pontos de discussão como única categoria na decolonialidade.

Mesmo com seus próprios debates teóricos e visões, não necessariamente iguais, as referidas autoras tentam fugir com certa similaridade de uma "hierarquização de importância" das áreas de gênero, raça e classe nos estudos decoloniais.

Cusicanqui (2010) busca compreender como a decolonialidade e gênero insere-se nas pautas eurocêntricas da realidade latino-americana e como elas são fomentadas e adequadas às mulheres que sofrem com a exclusão patriarcal e colonial.

As mulheres têm força para construir uma narrativa crítica, capaz de desmascarar as diferentes formas de colonialismo contemporâneo patriarcal. No contexto de um desenvolvimento histórico que as hierarquizou, vemos histórias marcadas pela subordinação e exploração da época colonial. (CUSICANQUI, 2010, p. 5).

Segundo Graças (2017), para compreender a questão de gênero na decolonialidade, Cusicanqui (2010) utiliza-se da situação das mulheres latino-americanas para denunciar a reprodução dos modos de colonização no seio das (ex) colônias através da subjugação, dominação, escravidão ou do sistema patriarcal imposto às mulheres dessas sociedades. Nos estudos de Cusicanqui (2010), encontramos as análises para entender como o sistema de gênero das sociedades que foram colonizadas está vinculado ao sistema de gênero colonial, isto é, seu alicerce são as relações culturais de gênero advindas do processo civilizatório, no qual há uma hierarquia entre homens e mulheres. Essas duas categorias fechadas não abriam espaço para debates e discussões acerca do terceiro gênero, gays, lésbicas etc. Essa hierarquia foi estendida para as categorias raça, etnia e classe. A situação das mulheres colonizadas se distingue pelo fato de terem sofrido e sofrerem com a colonização das grandes metrópoles e também por sofrerem o colonialismo interno. Ou seja, essas mulheres foram condicionadas a um padrão de comportamento e de vida distante de sua cultura e esse padrão foi/é reproduzido na nova sociedade imposta pelo Ocidente.

Nos debates de Segato (2012), percebemos uma preocupação em desenvolver uma análise da estrutura patriarcal ${ }^{11}$ no cotidiano do gênero em relação à vida social.

\footnotetext{
${ }^{11}$ Estrutura simbólica patriarcal é um conceito usado pela antropóloga feminista Rita Segato (2003), no qual o resultado das relações simbólicas horizontais entre os pares masculinos fundadas na ideia de contrato sexual que determinam suas relações simbólicas verticais com os pares femininos. "O contrato sexual é uma ideia análoga a de contrato social formulada pela feminista Carole Pateman (1988) para compreender, em oposição às leituras clássicas sobre o tema, a instituição do patriarcado" (SEGATO, 2003, p. 19).
} 
Segundo Pereira (2007, p. 463-464),

As análises de Segato (2012) residem na possibilidade de repensar as políticas públicas direcionadas à violência contra a mulher. A autora enfatiza questões cruciais, muitas vezes negligenciadas nas análises sobre violência de gênero: a dimensão expressiva e não apenas instrumental dos crimes contra as mulheres e a presença da interlocução entre os agentes interlocução tanto ou mais importante que a conexão imediata entre agressor e vítima. Essa ênfase possibilita pensar novos caminhos e fendas inexploradas. Quando as políticas públicas se centram mais no perpetrador, olvidando-se do intenso processo de comunicação do ato violento, com certeza, muito do essencial é deixado de lado, impedindo a eficácia das ações.

Outra contribuição da autora repousa na forma de construir seu olhar. Muitas das análises de gênero e de violência de gênero que se querem objetivas e científicas acabam caindo numa armadilha: ao espelhar a construção de sua narrativa numa estrutura epistemológica disciplinar cerrada, acabam replicando a voz de um sujeito branco, masculino, heterossexual e pertencente às elites.

Walsh (2007) procura trazer a decolonialidade do gênero como elemento na teorização sobre a colonialidade do poder, cuja meta é lutar pelo poder interpretativo das teorias feministas, a partir de um projeto de descolonização do saber eurocêntrico-colonial, como a autora chama de: pensamiento próprio latino-americano.

Neste sentido, "pensamiento próprio" é sugestivo de um pensamento crítico diferente, que pretende marcar uma divergência com o pensamento dominante 'universal' (incluindo suas vertentes críticas, progressistas e de esquerda). Essa divergência não se destina a simplificar o pensamento indígena ou negro, ou relegá-lo à categoria ou estatuto de pensamento localizado, situado e culturalmente específico e concreto, isto é, como nada mais que 'conhecimento local' entendido como mera experiência. Pelo contrário, é apresentar seu caráter político e descolonial, permitindo uma conexão entre os vários "pensamientos propios" como parte de um projeto mais amplo de pensamento crítico e "outros" conhecimentos. (WALSH, 2007, p. 231).

Nos estudos e reflexões de Costa (2010):

Apesar de Walsh (2007) não fazer nenhuma menção em seu artigo às teorias feministas que surgem na América Latina como parte integrante do movimento de descolonização do saber, gostaria aqui de apropriar sua discussão - sobre a geopolítica do conhecimento e a necessidade de construção de novas cosmologias e epistemologias a partir de "outros" lugares de enunciação - para incluir o feminismo dentre esses "outros" espaços de teorização, interpretação e intervenção na América Latina. (COSTA, 2010, p. 51). 
Durante a construção deste trabalho de pesquisa, pôde-se perceber que as três autoras principais encontradas para o debate teórico de decolonialidade e gênero possuem combinações específicas pertinentes a cada uma, relativas aos principais pontos de discussão: gênero, raça e classe, mapeados nos artigos encontrados nas bases de dados, durante a revisão sistemática de literatura.

Corroborando com Bezerra (2018), observamos nos debates teóricos dos artigos a supremacia masculina de estrutura de desigualdades nas relações entre homens e mulheres, que as prejudicam. No entanto, essas desigualdades assumem configurações particulares quando presentes nos enquadramentos de classe e raça. As formas de opressão tanto ideológicas como propriamente materiais vividas pelas mulheres pensadas nos estudos de decolonialidade analisados nesse trabalho possuem cada uma a sua particularidade.

Durante a finalização desse trabalho de pesquisa, percebemos como, mesmo nos estudos decoloniais, que oferecem uma desconstrução e tentam romper com o "padrão" colonial europeu nos estudos acadêmicos, ainda encontramos a categoria gênero, ainda invisibilizada e/ou silenciada, principalmente atingindo às autoras mulheres, que ainda não têm a equidade de alcance de artigos de autores masculinos.

É importante apresentar tais considerações, uma vez que são realidades trazidas de dentro da academia e ainda podem ser observadas como fatores simbólicos de dominação patriarcal sobre as mulheres. Por outro lado, nos textos encontrados, vemos a todo o momento uma tentativa de quebras de estruturas coloniais de dominação, com as pesquisas que dão voz aos sujeitos invisibilizados, e que tentam demonstrar e valorizar os estudos de gênero sob a óptica de contribuição de autoras que também foram pioneiras nos estudos decoloniais. Nesse caso, numa perspectiva decolonial, estaremos enfim realizando o movimento reflexivo para romper com a noção de colonialidade e marcando as análises de decolonialidade com suas identidades e contribuições na tentativa de desnaturalização de hierarquias, rejeitando os poderes coloniais e contribuindo para toda dimensão de investigações que tenham a abordagem de gênero.

\section{Referências}

BADINTER, E. Rumo equivocado: o feminismo e alguns destinos. Rio de Janeiro: Civilização Brasileira, 2005.

BALLESTRIN, L. América Latina e o giro decolonial. Revista Brasileira de Ciência Política, Brasília, n. 11, p. 89-117, 2013. Doi: 10.1590/S0103-33522013000200004. 
BEZERRA, L. Gênero, raça e classe: um olhar interseccional sobre a violência simbólica no cotidiano da universidade. Revista Feminismos, Salvador, v. 6, n. 2, maio-ago. 2018.

BUTLER, J. Problemas de gênero: feminismo e subversão da identidade. Rio de Janeiro: Civilização Brasileira, 2003.

BUTLER, J. Actos perfomativos e constituição de género. Um ensaio sobre fenomenologia e teoria feminista. In: MACEDO, A. G.; RAYNER, F. (org.). Gênero, cultura visual e performance: antologia crítica. Minho: Universidade do Minho/Húmus, 2011.

CASHMORE, E. Dicionário de relações étnica e raciais. São Paulo: Selo Negro, 2000.

COLAÇO, T. L. Novas perspectivas para a antropologia jurídica na América Latina: o direito e o pensamento decolonial. Florianópolis: Fundação Boiteux, 2012.

COSTA, C. L. Feminismo, tradução cultural e a descolonização do saber. Fragmentos, Florianópolis, v. 21, n. 2, 2010.

CURIEL, O. Descolonizando el feminismo: una perspectiva desde América Latina y el Caribe. In: PRIMER COLOQUIO LATINOAMERICANO SOBRE PRAXIS Y PENSAMIENTO FEMINISTA. 2009. Disponível em: http://bdigital.unal.edu.co/39749/. Acesso em: 19 jun. 2019.

CUSICANQUI, S. R. Ch'ixinakak utxiwa: una reflexión sobre prácticas y discursos descolonizadores. Buenos Aires: Tinta Limón Ediciones, 2010.

DIAS, L. O. O feminismo decolonial de Maria Lugones. In: ENCONTRO DE ENSINO PESQUISA E EXTENSÃO - ENEPED, 5., Dourados, 2013. Anais [...].Dourados: Editora da UFGD, 2013.

ESPINOSA-MIÑOSO, Y. Una crítica descolonial a la epistemologia feminista crítica. El Cotidiano, México, n. 184, mar.-abr. 2014.

FIGUEIREDO, C. V. S. Estudos subalternos uma introdução. Raído, Dourados, v. 4, n. 7, 2010.

GALVÃO, T. F.; PEREIRA, M. G. Revisões sistemáticas da literatura: passos para sua elaboração. Epidemiol. Serv. Saúde, Brasília, v. 23, n. 1, mar. 2014. Doi: 10.5123/S167949742014000100018.

GOMES, C. M. Gênero como categoria de análise decolonial. Civitas, Porto Alegre, v. 18, n. 1, 2018. Doi: 10.15448/1984-7289.2018.1.28209.

GONZATTO, R. Como se escreve: decolonial ou descolonial? 2015. Disponível em http://www.gonzatto.com/decolonial-ou-descolonial/. Acessado em: 8 maio 2019.

GRAÇAS, S. T. Gênero e raça na contemporaneidade: um diálogo entre Silva Rivera Cusicanqui e a Marcha Mundial das Mulheres. Caderno de Relações Internacionais, v. 10, n. 1, 2017. Doi: 10.17771/PUCRio.CadRI.30425. 
LIMA COSTA, C. Feminismos decoloniais para além do humano. Estudos Feministas, Florianópolis, v. 22, n. 3, set.-dez. 2014. Doi: 10.1590/S0104-026X2014000300012.

LANDER, E. (org.). A colonialidade do saber: eurocentrismo e ciências sociais: perspectivas latinoamericanas, Buenos Aires: Clacso, 2005. (Colleción Sur Sur).

LUGONES, M. Colonialidad y género. Tabula Rasa, Bogotá, n. 9, jul.-dic. 2008. Doi: $10.25058 / 20112742.340$.

LUGONES, M. Heterosexualism and the colonial: modern gender system. Hypatia, v. 22, n. 1, 2007. Doi: 10.1353/hyp.2006.0067.

LUGONES, M. Subjetividad esclava, colonialidad de género, marginalidad y opresiones múltiples. In: LUGONES, M. Pensando los feminismos en Bolivia. La Paz: Bolivia, 2012. P. 129-140. (Série Foros, 2).

LUGONES, M. Rumo a um feminismo decolonial. Revista de Estudos Feministas, Florianópolis, v. 22, n. 3, 2014. Doi: 10.1590/S0104-026X2014000300013.

MENDOZA, B. La epistemología del sur, la colonialidad del género y el feminismo latinoamericano. In: MINOSO, Y. E. (org.). Aproximaciones críticas a las prácticas teóricopolíticas del feminismo latinoamericano. Buenos Aires: En la Frontera, 2010.

OLIVEIRA, L. F.; CANDAU, V. M. F. Pedagogia decolonial e educação antirracista e intercultural no Brasil. Educação em Revista, Belo Horizonte, v. 26, n.1. p. 15-40, 2010. Doi: 10.1590/S0102-46982010000100002.

PEREIRA, P. P. G. As estruturas elementares da violência. Cadernos Pagu, Campinas, v. 29, jul.-dez. 2007. Doi: 10.1590/S0104-83332007000200018.

PISCITELLI, A. Recriando a (categoria) mulher? In: ALGRANTI, L. (org.). A prática feminista e o conceito de gênero. Campinas: IFCH/Unicamp, 2012. p. 7-42. (Textos Didáticos, 48).

QUIJANO, A. Colonialidade do poder e classificação social. In: SANTOS, B. S.; MENESES, M. P. (org.). Epistemologias do sul. São Paulo: Cortez, 2010. p. 73-118.

SANTOS, G. Novos atores sociais nas políticas culturais: reflexões sobre a participação social nas políticas para culturas populares. In: SEMINÁRIO INTERNACIONAL DE POLÍTICAS CULTURAIS, 2., 2011, Rio de Janeiro. Anais [...]. Rio de Janeiro: Fundação Casa de Rui Barbosa, 2011.

SEGATO, R. Gênero e colonialidade: em busca de chaves de leitura e de um vocabulário estratégico descolonial. E-Cadernos CES, Coimbra, 2012. Doi: 10.4000/eces.1533.

SPIVAK, G. Pode o subalterno falar? Belo Horizonte: Editora da UFMG, 2010. 
WALSH, C. Interculturalidade crítica e pedagogia decolonial: in-surgir, re-existir e re-viver. In: CANDAU, V. M. (org.). Educação intercultural na América Latina: entre concepções, tensões e propostas. Rio de Janeiro: 7 Letras, 2009. p. 12-43.

WALSH, C. (ed.). Pedagogías decoloniales: prácticas insurgentes de resistir, (re)existir y (re)vivir. Quito, Ecuador: Ediciones Abya-Yala, 2013.

WALSH, C. Shifting the geopolitics of critical knowledge: decolonial thought and cultural studies "others" in the Andes. Cultural Studies, v. 21, 2007. Doi: $10.1080 / 09502380601162530$.

Submetido em 21 de agosto de 2019.

Aprovado em 17 de outubro de 2019. 